\title{
Chromosome Complements in the Spermatogenesis of Two Penaeid Prawns, Penaeus merguiensis and $P$. esculentus
}

\author{
J-H Xiang ${ }^{1}$, A. J. Courtney ${ }^{2}$ and L-H Zhou ${ }^{1}$ \\ ${ }^{1}$ Institute of Oceanology, Academia Sinica, Qingdao 266071, China \\ ${ }^{2}$ Queensland Department of Primary Industries, Southern Fisheries Centre, \\ PO Box 76 Deception Bay, Queensland 4508, Australia
}

Accepted June 19, 1996

Although the fisheries for, and mariculture of, penaeid prawns are of major commercial importance, there has been relatively little research undertaken on the chromosome number, structure and composition in the Penaeidae (Xiang 1988, Xiang et al. 1991). One reason for this is due to the relatively small size and large number of chromosomes, which makes production of histological material difficult.

In this paper, we report a simple and effective technique for determining chromosome complements during spermatogenesis in two species of penaeid prawns, Penaeus merguiensis and $P$. esculentus in Australia. The first estimates of the number of chromosomes in these species are given.

\section{Materials and methods}

Specimens. Specimens of $P$. esculentus and $P$. merguiensis were obtained by trawling in Moreton Bay $\left(27^{\circ} \mathrm{S}, 153^{\circ} \mathrm{E}\right)$ southeast Queensland. The prawns were sorted from the by-catch and kept alive by placing them in fresh, aerated seawater. Only males were used for chromosome preparations. The total lengths of the individuals were $71-132 \mathrm{~mm}$ for $P$. esculentus and 130-140 mm for P. merguiensis.

Tissues. The prawns were injected with $0.1-0.3 \mathrm{ml}$ of $0.2 \%(\mathrm{w}: \mathrm{w})$ colchicine solution into the muscle of the first or the second abdominal segment, and kept alive in seawater for 4$5 \mathrm{hr}$. Individual prawns were then sacrificed, the testis dissected out and cut into $2-3 \mathrm{~mm}$ pieces. The testicular tubules were placed in $0.7 \%(\mathrm{w}: \mathrm{w}) \mathrm{KCl}$ solution for $30-35 \mathrm{~min}$. The hypotonized testicular tissue were then fixed for 15-20 min in fresh Carnoy's solution (methanol:acetic acid at $3: 1)$. The fixative was then changed twice; firstly at the same $(3: 1)$ methanol : acetic acid concentration for $15 \mathrm{~min}$, and then at a ratio of $1: 1$, for a further $15 \mathrm{~min}$. The fixed tissues were stored in a refrigerator at $4{ }^{\circ} \mathrm{C}$ until histological preparation.

Chromosome preparation and observation. One or two small pieces of tissue were placed on a clean slide with $2-3$ drops of fresh fixative $(3: 1)$, smeared and spread using forceps. The wet slide was left at room temperature for partial drying. The preparations were stained with $5 \%$ Giemsa with a phosphate buffer $(\mathrm{pH}=7.0)$. After immersing in the Giemsa stain for 15$20 \mathrm{~min}$ the slide was rinsed with running tap water and then with distilled water. Chromosome counts were made using an optical microscope and only on cells that were spread such that individual chromosomes did not physically touch one another or overlap. 


\section{Results and discussion}

The smeared testis lobes contained both meiotic and mitotic cells. The Giemsa staining provided a good contrast for photomicrographs of the chromosomes. Chromosome complements were determined mostly from primary spermatocytes (Fig. 1a), but also from mitotic spermatogonia during chromosomal metaphase. The meiotic bivalents were 4-6 $\mu \mathrm{m}$ in length and larger than the mitotic chromosomes which were $1-3 \mu \mathrm{m}$. The majority of the mitotic chromosomes in spermatogonia were of the "dot" shape, characteristic of the Decapoda.

Typical meiotic spermatocytes displaying the haploid complement of chromosomes can be seen for both $P$. esculentus and $P$. merguiensis in Figs. 1b, d, respectively. Mitotic spermatogonia displaying the diploid complement can be seen in Figs. 1c, e, for $P$. esculentus and $P$. merguiensis, respectively.

Chromosome counts from meiotic bivalents and mitotic spermatogonia in both $P$. esculentus and $P$. merguiensis are shown in Figs. $2 \mathrm{a}-\mathrm{d}$, respectively. There is a clear mode of 44 for the haploid number of chromosomes for both species (Figs. 2a, c, respectively). Although fewer mitotic spermatogonia were observed than the meiotic spermatocytes, the counts indicate a mode of 88 for the diploid number in both P. esculentus and P. merguiensis (Figs. 2b, d, respectively).

The production of a karyotype was not possible in this study due to the very small size of individual chromosomes.

Other species in the genus Penaeus, including P. duorarum, P. aztecus (Milligan 1976, Chow et al. 1990, Xiang et al. 1993), P. chinensis (or P. orientalis) (Xiang 1988, Dai et al. 1989), P. monodon (Xiang et al. 1990) and P. penicillatus (Xiang et al. 1991) have also been

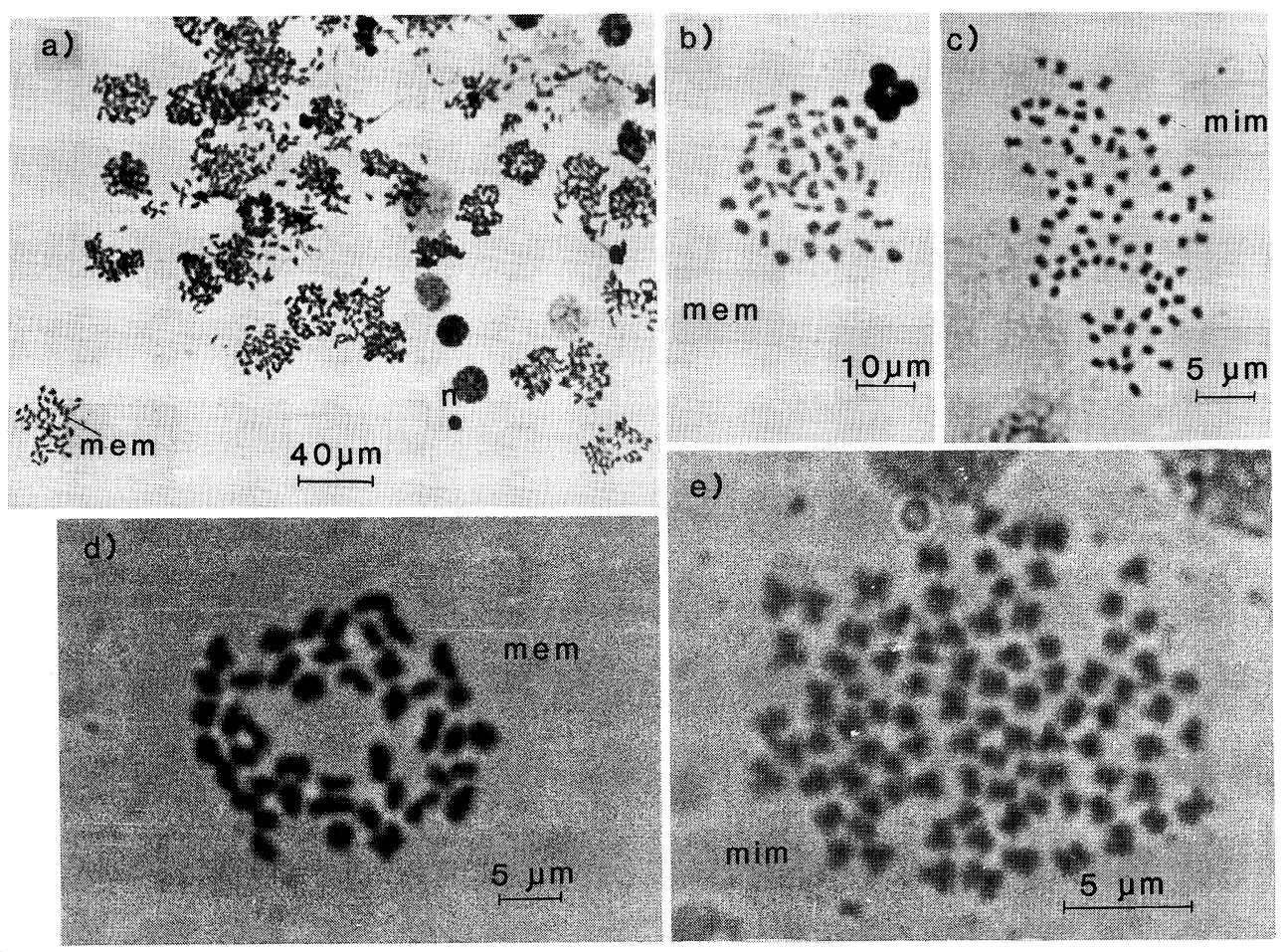

Fig. 1. Photomicrographs of the penaeid prawn chromosomes during spermatogenesis. a-c are $P$. esculentus; d, e are $P$. merguiensis; mem, spermatocytes undergoing meiotic metaphase; mim spermatogonia undergoing mitotic metaphase; $n$, nucleus. 

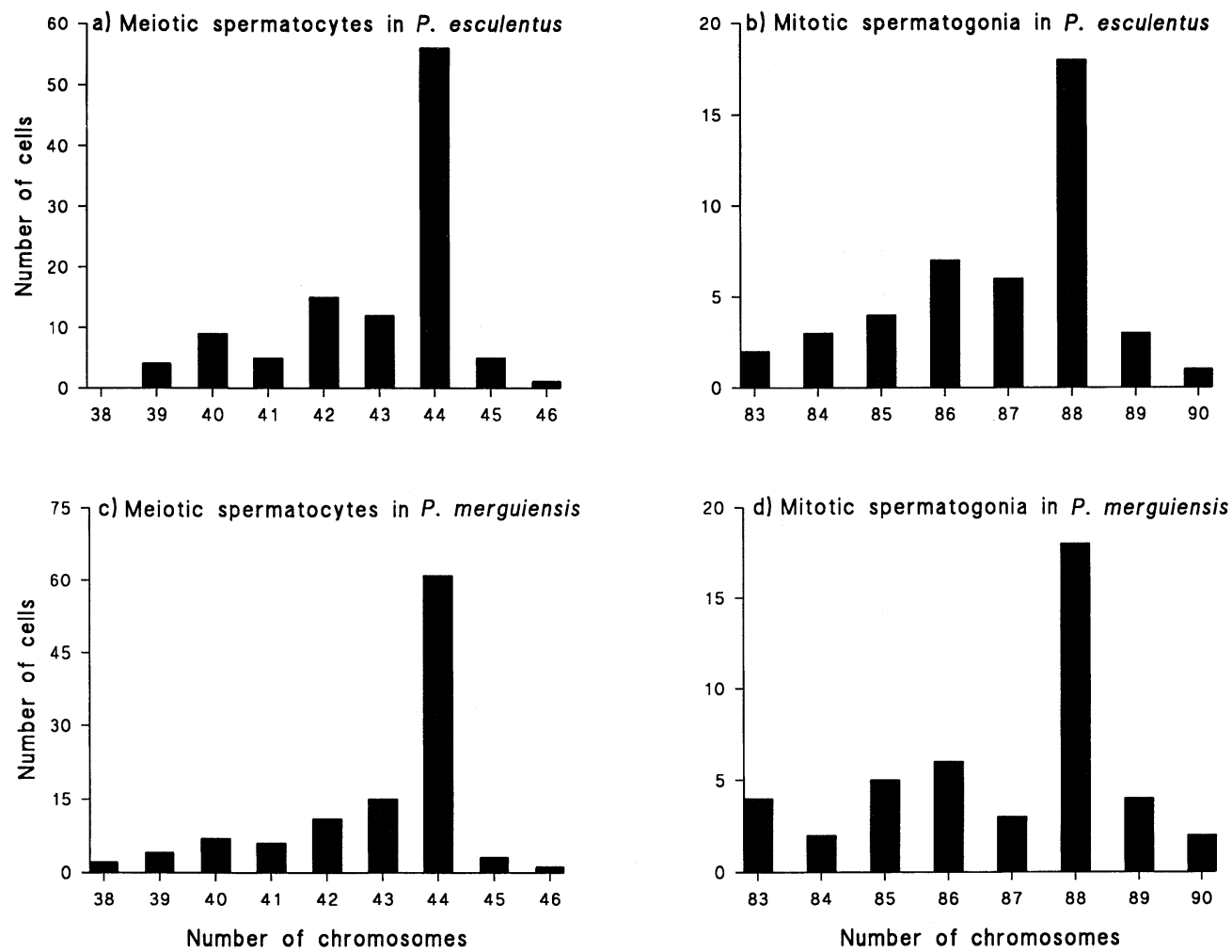

Fig. 2. Frequency distributions for haploid (a, c) and diploid (b, d) chromosome counts in $P$. esculentus and $P$. merguienis.

reported to have 44 haploid ( 88 diploid) chromosomes. Penaeus setiferus has been reported to have a diploid number of 90 and a haploid number of 45 (Milligan 1976, Chow et al. 1990, Xiang et al. 1993), as has $P$. semisulcatus (Xiang et al. 1991). The diploid number for $P$. japonicus has been reported to be 86 and the haploid number 43 (Hayashi and Fujiwara 1988, Xiang et al. 1991). The present study demonstrated that both $P$. esculentus and $P$. merguiensis have numbers of chromosomes which are similar to those found in other members of the genus.

\section{Acknowledgments}

This investigation was supported by an exchange program between Chinese Academy of Sciences and Australian Academy of Sciences and Chinese Project PDB6-5. J-H X is grateful for the support and encouragement provided by Mr. M. C. L. Dredge and the Queensland Department of Primary Industries.

\section{References}

Chow, S., Dougherty, W. J. and Sandifer, P. A. 1990. Meiotic chromosome complements and nuclear DNA contents of four species of shrimps of the genus Penaeus. J. Crustacean Biol. 10(1): 29-36.

Dai, J. X., Zhang, Q. Q. and Bao, Z. M. 1989. Karyotype studies on Penaeus orientalis. J. Ocean Univ. Qingdao 19(4): 97-104.

Hayashi, K. and Fujiwara, Y. (1988). A new method for obtaining metaphase chromosomes from the regeneration blastema of Penaeus (Marsupenaeus) japonicus. Nippon Suisan Gakkaishi 54: 1563-1565.

Milligan, D. J. 1976. A method for obtaining metaphase chromosome spreads from marine shrimp with notes on the 
karyotypes of Penaeus aztecus, Penaeus setiferus and Penaeus duorarum. Proceedings of the World Mariculture Society 7: 327-332.

Xiang, J. H. 1988. The chromosome study on Chinese shrimp, Penaeus orientalis Kishinouye. Oceanologia et Limnologia Sinica 19(3): 205-209.

-, Liu, R. Y., Zhou, L. H. and Wang, H. F. 1990. A study on the chromosome in a marine shrimp, Penaeus monodon. Annual Research Reports, Experimental Marine Biology Laboratory, Academia Sinica, 1: 115-121.

-, Zhou, L. H., Liu, R. Y. and Yu, D. G. 1991. The chromosomes of three shrimps, Penaeus penicillatus, P. semisulcatus and P. japonicus. Marine Sci. 4: 72-73.

- - - and Zhou, L. H. 1993. Chromosomes of marine shrimps with special reference to different techniques. Proceedings of the Fourth International Symposium on Genetics in Aquaculture (Eds. G. A. E. Gall and H. X. Chen) p. 321. Elsevier, Netherland. 